OPEN ACCESS

Edited by:

Alina M. Mihai,

Beacon Hospital, Ireland

Reviewed by:

Pierre Thirion

Trinity College Dublin, Ireland

Suneil Jain

Queen's University Belfast,

United Kingdom

*Correspondence:

Simon S. LO

simonslo@uw.edu

tThese authors have contributed equally to this work and share first authorship

Specialty section

This article was submitted to

Radiation Oncology

a section of the journal

Frontiers in Oncology

Received: 16 July 2019

Accepted: 24 October 2019

Published: 12 November 2019

Citation:

Wujanto C, Vellayappan B, Siva S,

Louie AV, Guckenberger M,

Slotman BJ, Onishi H, Nagata Y, Liu M

and Lo SS (2019) Stereotactic Body

Radiotherapy for Oligometastatic

Disease in Non-small Cell Lung

Cancer. Front. Oncol. 9:1219.

doi: 10.3389/fonc.2019.01219

\section{Stereotactic Body Radiotherapy for Oligometastatic Disease in Non-small Cell Lung Cancer}

\author{
Caryn Wujanto ${ }^{1+}$, Balamurugan Vellayappan ${ }^{1+}$, Shankar Siva ${ }^{2}$, Alexander V. Louie ${ }^{3}$, \\ Matthias Guckenberger ${ }^{4}$, Ben J. Slotman ${ }^{5}$, Hiroshi Onishi ${ }^{6}$, Yasushi Nagata ${ }^{7}$, Mitchell Liu ${ }^{8}$ \\ and Simon S. Lo ${ }^{9 *}$ \\ ${ }^{1}$ Department of Radiation Oncology, National University Cancer Institute Singapore, National University Health System, \\ Singapore, Singapore, ${ }^{2}$ Division of Radiation Oncology and Cancer Imaging, Peter MacCallum Cancer Centre, University of \\ Melbourne, Melbourne, VIC, Australia, ${ }^{3}$ Department of Radiation Oncology, Sunnybrook Health Sciences Centre, The \\ University of Toronto, Toronto, ON, Canada, ${ }^{4}$ Department for Radiation Oncology, University Hospital Zurich, Zurich, \\ Switzerland, ${ }^{5}$ Department of Radiation Oncology, Amsterdam University Medical Centers, Vrije Universiteit Amsterdam, \\ Amsterdam, Netherlands, ${ }^{6}$ Department of Radiology, University of Yamanashi, Kofu, Japan, ${ }^{7}$ Department of Radiation \\ Oncology, Graduate School of Biomedical Sciences, Hiroshima University, Hiroshima, Japan, ${ }^{8}$ Department of Radiation \\ Oncology, British Columbia Cancer Agency, Vancouver Centre, Vancouver, BC, Canada, ${ }^{9}$ Department of Radiation \\ Oncology, University of Washington School of Medicine, Seattle, WA, United States
}

Metastatic non-small cell lung cancer (NSCLC) is associated with a limited survival when treated with palliative intent platinum-based chemotherapy alone. Recent advances in imaging and therapeutic strategy have identified a subset of patients with limited metastases who may benefit from early local ablative therapy with either surgery or radiotherapy, in addition to standard treatment. Stereotactic body radiotherapy (SBRT) is increasingly used in the treatment of extra-cranial oligometastatic NSCLC (OM-NSCLC) due its non-invasive conduct and ability to deliver high doses. Clinical evidence supporting the use of SBRT in OM-NSCLC is emerging and consistently demonstrates significant benefit in local control and progression-free survival. Here, we discuss the definition of oligometastases (OM), review current available data on SBRT treatment in extra-cranial OM-NSCLC including evidence for site-specific SBRT in lung, liver, and adrenal metastases.

Keywords: stereotactic body radiotherapy, non-small cell lung cancer, lung cancer, oligometastases, oligometastatic disease

\section{INTRODUCTION}

Lung cancer continues to be the leading cause of cancer death in many countries (1). Unfortunately, about two-thirds of non-small cell lung cancer (NSCLC) patients present with metastatic disease (Stage IV) at diagnosis and are considered incurable (2). For these patients, systemic therapy continues to be the mainstay of treatment. However, with conventional chemotherapy alone, the median survival hovers around 10 months, and long-term survival is unlikely (3). There can be considerable heterogeneity within stage IV classification, with a sub-group of stage IV patients (especially those with low-volume metastatic disease) having prolonged survival. This led to the 8th edition of American Joint Committee on Cancer (AJCC) to further categorize stage IV. In particular, patients with a single extra-thoracic metastasis was classified as M1b (Stage IVA), as opposed to patients with multiple lesions in one or multiple organs (M1c, Stage IVB) (4). Precisely 
classifying these patients improves the prognostic value and in doing so, will help guide treatment; in particular, identifying patients with OM-NSCLC who may warrant aggressive management of the primary tumor, as well as the metastatic sites.

The term "oligometastatic" disease has been used commonly (and sometimes loosely) in the cancer literature ever since 1995. Hellman and Weichselbaum were the first to introduce this concept of OM disease, which represented an intermediate state in the spectrum between locally confined and widely metastatic cancer $(5,6)$. They proposed that the process of metastatic disease occurs in a step-wise manner, and patients with limited disease should be managed aggressively. In more recent years, advances in systemic/targeted therapy may render a greater proportion of patients with upfront widely metastatic disease to a state of limited volume metastatic disease. In these patients, aggressive management of drug-resistant clones may improve cancer outcomes.

Surgical metastasectomy was initially the only way to radically manage these patients (7). With the advent of intracranial stereotactic radiosurgery, high doses of ablative radiation delivered over a limited number of fractions were seen to be as effective as surgical resection $(8,9)$. Advances in imaging, treatment delivery and patient immobilization now allow us to perform ablative radiation to extra-cranial sites in the form of stereotactic body radiotherapy (SBRT) (10). SBRT has an advantage over surgical metastasectomy in that it is non-invasive, well-tolerated and has fewer interruptions to systemic therapy.

In this mini-review, we will discuss the definitions of $\mathrm{OM}$ disease (in the context of NSCLC), patient selection, prognostic factors as well as completed and ongoing trials to support the use of SBRT for OM-NSCLC.

\section{INCIDENCE AND DEFINITION OF OLIGOMETASTATIC CANCER}

To date, there is no universal definition of what constitutes $\mathrm{OM}$ with regards to the number of lesions or sites involved. The most accepted number of metastatic lesions is considered to be 5 or less (with up to 3 metastases in an organ) (11-14).

As definitions of OM vary from study to study, it is hard to estimate the exact incidence of OM in NSCLC at diagnosis. Moreover, the routine use of staging FDG/PET-CT scan and MRI brain imaging may increase the incidence of OM, due to increased sensitivity compared to older imaging modalities. The International Association for the Study of Lung Cancer (IASLC) Lung Cancer staging project found that 225 out of 1,025 (22\%) patients had synchronous single metastatic lesion at diagnosis; this group of patients had a better prognosis compared to patients with metastases in multiple organs (15). In another study by Parikh et al., $26 \%$ of patients had 5 or fewer metastases at diagnosis, and half of these patients only had 1 metastases (16).

In terms of classifying oligometastatic cancer, there are three possible scenarios:

1) Synchronous oligometastatic disease: Patients who present with up to 5 metastatic lesions (in one or a few organs) at first or within 6 months of diagnosis. These typically occur in the brain, lung parenchyma, liver or bone (15).

2) Oligo-residual (or oligo-persistent) disease: Widely metastatic disease $(>5)$ at diagnosis, which has responded well to systemic therapy (i.e., complete response), with the remaining lesions (up to 5) amenable to radical local therapy (e.g., surgery, SBRT, RFA) (17).

3) Metachronous (or oligo-recurrence): Patients who had been treated with curative intent, and then present with limited sites of metastatic disease (up to 5) after an interval of stable disease (18).

As oligoprogression is a biologically distinct entity whereby patients with upfront widespread metastases progress, in a limited number of sites, after initially achieving stable disease or partial response, we have not included it in this definition. It is possible that patients with oligoprogression have a worse prognosis compared to the above scenarios.

\section{CHOICE OF LOCAL THERAPY: BETWEEN SURGERY, SBRT, AND RADIOFREQUENCY ABLATION}

Selecting the most effective method for local treatment of oligometastases requires thoughtful considerations. Patientrelated factors (e.g., age, performance status and organ function, patient preferences), tumor-related factors (e.g., location, size, proximity to vessels or nearby critical organs) and treatmentrelated factors (e.g., availability of expertise, cost, and waiting list) have to be taken into account.

In the latest National Comprehensive Cancer Network (NCCN) guideline for stage IVA NSCLC, definitive RT to OM, with particular mention of SBRT, is recommended as an appropriate option in suitable patients with good performance status provided it can be delivered safely (19). This reflects a growing trend and clinical evidence supporting the use of SBRT for OM. A survey of 1,007 radiation oncologists from 43 countries published by Lewis et al. in 2017 reported that $83 \%$ have been using SBRT for extracranial OM since 2005 (with over 30\% since 2010) with treatment response and durability as the main reason for choosing SBRT (20). The survey reported the most common treated organs were lung, liver, and spine $(90,75$, and $70 \%$, respectively).

There are no head-to-head studies comparing surgery, SBRT, and RFA. In liver metastases, SBRT is superior to RFA in treating larger lesions $>3 \mathrm{~cm}$, or for lesions near blood vessels where there can be a heat-sink effect with RFA $(21,22)$. Widder et al. retrospectively analyzed 110 patients with pulmonary OM who were offered surgery as first line treatment for OM and SBRT if they were unsuitable for surgery (23). Although SBRT was offered as an alternative option, OS and local control rates were comparable between the two groups. As such, due to its noninvasive conduct and ability to deliver highly conformal high dose radiotherapy, SBRT has been increasingly used to target OM lesions especially for patients with technically unresectable lesions or those who are unfit for surgery. 


\section{PROGNOSTIC FACTORS AND PATIENT SELECTION}

Patient selection is not only important to ensure the safe delivery of SBRT but also has prognostic significance (24). Several previous studies have attempted to streamline patient selection through identifying prognostic factors.

In a retrospective cohort study involving 186 patients, ECOG performance status $>2$, higher nodal-status (N2-3), squamous histology and metastases to multiple organs were associated with a worse prognosis (16). Ashworth and colleagues performed an individual patient meta-analysis using data from 757 patients treated curatively at the primary site, and with up to 5 metastatic lesions, treated radically with local therapies such as surgical resection, SBRT, high-dose radical RT (25). Surgery was the most commonly used treatment for the primary site $(83.9 \%)$ and the metastatic sites (62.3\%). The median survival of these patients was 26 months, and approximately a third survived 5 years. Key findings from this study are that patients with metachronous metastases, lower $\mathrm{N}$ status and adenocarcinoma histology were predicted to have longer OS. The authors proposed stratifying patients into three risk groups: low-risk (metachronous metastases, 5-year OS 47.8\%), intermediate-risk (synchronous metastases with N0 disease, 5-year OS 36.2\%), and high-risk (synchronous metastases with N1/N2 disease, 5-year OS $13.8 \%$ ) (25), however this classification scheme is yet to be formally validated in clinical trials.

The number (and possibly volume) of metastatic sites has also been shown to be a potential prognostic factor. In a SWOG study by Albain et al., involving 2,531 patients with advanced NSCLC, median survival was highest in patients with a single lesion (8.7 months), compared to patients with multiple lesions in one organ (6.2 months) and multiple lesions in multiple organs (5.1 months) (26). Similarly in the subgroup analysis of RTOG 9508 trial, which allowed up to 3 brain metastases, survival improvement (with the addition of stereotactic radiosurgery) was only found in patients with a single lesion compared to 2-3 lesions (27). Looking at the use of SBRT in particular, patients with up to 3 lesions had a better OS compared to patients with 4-5 lesions (2-year OS 60.3 vs. $21.9 \%$ ). However, it must be noted that only 11 of 61 patients had NSCLC (28).

\section{SBRT TO EXTRA-CRANIAL SITES COMMONLY SEEN WITH OLIGOMETASTATIC NSCLC (LUNG, LIVER, ADRENAL)}

A) Lung: Prior studies on SBRT in primary NSCLC have reported local control rate comparable to surgery when the biologically effective dose (BED) of SBRT was at least $100 \mathrm{~Gy}$ (29-32). De Rose et al. reviewed 60 patients treated with SBRT for lung metastases in NSCLC with 60 Gy in 3 fractions to peripheral lesions $<2 \mathrm{~cm}, 48 \mathrm{~Gy}$ in 4 fractions to peripheral lesions between 2 and $5 \mathrm{~cm}$, and $60 \mathrm{~Gy}$ in 8 fractions to central lesions (30). All patients received a BED > 100 Gy resulting in a 2 -year local control rate of $88.9 \%$ and 1 - and 2 -year OS of
94.5 and $74.6 \%$, respectively. Laterality of metastatic disease does not seem to influence survival outcomes. For example, the survival was not significantly different between ipsilateral (T4, M0) vs. contralateral (M1a) surgical metastasectomy in 43 patients with NSCLC (27 vs. 43\%) (33). Notably, none of the patients with mediastinal node involvement achieved long-term survival. More accurate staging with FDG-PET scan prior to SBRT significantly improved 1- and 2-year OS (82.7 vs. $72.8 \%$ and 64.8 vs. $52.6 \%$, respectively, $P=$ 0.012) (34). Pre-treatment performance status, maximum metastasis diameter, primary tumor histology, number of metastases, and time interval between primary tumor diagnosis and SBRT treatment significantly influenced OS (35). SBRT to the lung is generally well-tolerated with most patients experiencing grade 1-2 late pulmonary toxicity and grade 3 pulmonary toxicity in the minority $(30,31)$ and the BED at the planning target volume (PTV) isocenter was the only factor reported to influence toxicity in a database analysis of 700 patients treated with SBRT for oligometastatic lung disease (35).

B) Liver: Ahmed et al. evaluated the radiosensitivity of liver metastases from different primary histology using a multigene expression index for tumor radiosensitivity (RSI) (36). They suggested that NSCLC has an intermediate radiosensitivity (median RSI 0.31). Majority of the series reporting outcome of SBRT to liver metastases involve colorectal primaries. In the context of NSCLC, the presence of liver metastases has been associated with a worse prognosis compared to metastases to other sites in $\operatorname{NSCLC}(37,38)$. Milano et al. evaluated the use of $50 \mathrm{~Gy}$ in 5 fractions for SBRT to treat hepatic metastases ( $20 \%$ lung primary) and reported a 2-year local control rate of $67 \%$ (39). Rusthoven et al. (also $\sim 20 \%$ lung primary) reported a higher 2-year local control rate of $92 \%$ with SBRT regimen of 30-60 Gy in 3 fractions (40). In a pooled analysis involving 474 patients with 623 liver metastases (with mainly colorectal and breast primary), increasing the maximum isocenter BED to $>150$ Gy EQD2Gy, increased 1- and 2-year control rate of treated lesions from $77-83 \%$ and $64-70 \%$, respectively (41).

C) Adrenal: SBRT to adrenal metastases in OM-NSCLC was specifically evaluated in a study by Celik et al. whereby 15 patients received $42 \mathrm{~Gy}$ in 6 fractions of CyberKnife ${ }^{\circledR}$ SBRT (42). One and two-year local control rates were 60 and $46.6 \%$, respectively. Patient with metachronous metastases had a more favorable 2-year overall survival of $91.2 \%$ compared to $42.8 \%$ in patients with synchronous adrenal metastases. Holy et al. reported an overall median PFS of 4.2 months in their group of 18 patients with adrenal metastases from NSCLC treated with SBRT (range 20-40 Gy in 5 fractions) (43). Of these, 13 patients with isolated adrenal metastasis had longer median PFS of 12 months, local control rate of $77 \%$ (median follow-up: 21 months), and median OS of 23 months. SBRT for adrenal metastases is reasonably tolerated with previous studies reporting grade 1-2 toxicities including gastrointestinal toxicity, fatigue, rarely duodenal ulcers, and possibly late adrenal insufficiency $(42,44,45)$. 
TABLE 1 | Selected studies of SBRT treatment in oligometastatic NSCLC.

\begin{tabular}{|c|c|c|c|c|c|c|c|c|c|}
\hline References & Year & $\begin{array}{l}\text { Patients } \\
\text { (n) }\end{array}$ & $\begin{array}{l}\text { Site of } \\
\text { oligo-met }\end{array}$ & $N$ & $\begin{array}{l}\text { Dose } \\
\text { (Gy/fraction) }\end{array}$ & $\begin{array}{l}\text { Systemic } \\
\text { therapy }\end{array}$ & $\begin{array}{c}\text { Median } \\
\text { follow-up } \\
\text { (months) }\end{array}$ & $\begin{array}{l}\text { Median PFS } \\
\text { (months) }\end{array}$ & $\begin{array}{l}\text { Median OS } \\
\text { (months) }\end{array}$ \\
\hline \multicolumn{10}{|c|}{ RETROSPECTIVE STUDIES } \\
\hline Inoue et al. (47) & 2010 & $41^{\star}$ & $\begin{array}{l}\text { Brain, lung, } \\
\text { adrenal }\end{array}$ & $<5$ & $\begin{array}{l}\text { 48/8 (adrenal) } \\
\text { 35-60/4-8 (lung) }\end{array}$ & NA & 20 & $\begin{array}{l}\text { 3-year PFS } \\
20 \%\end{array}$ & 24 \\
\hline Holy et al. (43) & 2011 & 18 & Adrenal & NA & $20-40 / 5$ & Various & 21 & $\begin{array}{l}4.2 \text { (all) } \\
12 \text { (1 met) }\end{array}$ & 23 (1 met) \\
\hline Hasselle et al. (48) & 2012 & 25 & Multiple & $<5$ & $24-70 / 3-20$ & $\begin{array}{l}\text { Chemo or } \\
\text { targeted } \\
\text { therapy }\end{array}$ & 14 & 7.6 & 22.7 \\
\hline De Rose et al. (30) & 2016 & 60 & Lung & $<5$ & $48-60 / 3-8$ & Chemo & 28 & $\begin{array}{l}32.2 \\
\text { (actuarial) }\end{array}$ & 32.1 (actuarial) \\
\hline Celik et al. (42) & 2017 & 15 & Adrenal & $<5$ & $42 / 6$ & Chemo & 24 & 10.5 & 2-year OS 46.6\% \\
\hline \multicolumn{10}{|c|}{ SINGLE ARM PROSPECTIVE TRIALS } \\
\hline Salama et al. (28) & 2012 & $61^{*}$ & Multiple & $<5$ & $24-48 / 3$ & Chemo & 20.9 & $\begin{array}{l}\text { 2-year PFS } \\
22 \%\end{array}$ & 2-year OS 56.7\% \\
\hline $\begin{array}{l}\text { De Ruysscher } \\
\text { et al. (49) }\end{array}$ & 2012 & 40 & Multiple & $<5$ & $54 / 3^{\star \star}$ & Chemo & 27.7 & 12.1 & 13.5 \\
\hline Collen et al. (50) & 2014 & 26 & Multiple & $<5$ & $50 / 10$ & Chemo & 16.4 & 11.2 & 23 \\
\hline \multicolumn{10}{|c|}{ RANDOMIZED PHASE II TRIALS } \\
\hline Gomez et al. (12) & 2016 & 49 & Multiple & $<3$ & NR & Chemo & 12.4 & 14.2 vs. 4.4 & 41.2 vs. 17 \\
\hline lyengar et al. (11) & 2018 & 29 & Multiple & $<5$ & $21-37.5 / 1-5$ & Chemo & 9.6 & 9.7 vs. 3.5 & Not reached vs. 17 \\
\hline Palma et al. (13) & 2019 & 99 & Multiple & $<5$ & $35-60 / 3-8$ & Chemo & 25 & 12 vs. 6 & 41 vs. 28 \\
\hline
\end{tabular}

N, number of oligometastatic lesions per patient; OS, overall survival; NR, data not reported; PFS, progression free survival.

${ }^{\star}$ Various primary histology including NSCLC. ${ }^{* \star}$ Only one patient received SBRT.

\section{SUMMARY OF EVIDENCE SUPPORTING SBRT IN OM-NSCLC}

A retrospective analysis of patterns-of failure after first-line systemic therapy in 387 patients with NSCLC reported local progression as the predominant pattern-of failure and suggested that local consolidative therapy with SBRT to known sites of disease following systemic therapy to prolong the time to first progression (46). Since then, trials of patients with limited metastatic NSCLC treated with SBRT have demonstrated significant survival benefit in both first and second line settings (Table 1).

\section{Single Arm Prospective Trials}

1) Collen et al. reported on 26 patients with synchronous OM-NSCLC patients with up to 5 metastases treated with SBRT (50 Gy in 10 fractions) (50). Notably, patients with uncontrolled primary tumors were eligible. The primary endpoint was complete metabolic response (CMR) on PET ( 3 months post-SBRT). Seventeen patients underwent SBRT after upfront chemotherapy, and the remaining underwent SBRT (to all sites) as primary treatment. Sixty percent of patients achieved metabolic response, with half of reaching CMR. The median PFS was 11.2 months, and median OS 23 months.

2) De Ruysscher et al. included 40 patients with synchronous OM-NSCLC ( $\leq 5$ lesions) who were amenable for radical therapy to all tumor sites including the primary (surgery, stereotactic radiosurgery, fractionated RT to a dose of $60 \mathrm{~Gy}$, and one patient received treatment with $54 \mathrm{~Gy}$ in 3 fractions of SBRT) (49). The vast majority had a single metastatic focus, and were treated with upfront chemotherapy, and approximately half had brain metastases. They report a median PFS of 12.1 months, and OS of 13.5 months. The inferior results compared to the Collen study may be related the larger proportion of patients with brain metastases in this cohort, or the use of conventionally fractionated RT.

3) Bauml et al. recently published their single-arm Phase II trial comprising of 51 patients with $\leq 4$ lesions who completed locally ablative therapy to all sites, following which they were given pembrolizumab. They reported a median PFS of 19.1 months and 1-year OS of $90.9 \%$. This is notably much improved compared to historical controls (51).

\section{Randomized Phase II Trials}

1) Iyengar et al. then conducted a randomized phase II trial for 29 patients with NSCLC and up to 5 OM lesions. NSCLC who had achieved partial response or stable disease to firstline chemotherapy (11). EGFR/ALK positive patients were excluded. They were randomized to SBRT + maintenance chemotherapy vs. maintenance chemotherapy alone. The trial was stopped early due to significant improvements with the addition of SBRT (PFS 9.7 vs. 3.5 months, $P=0.01$ ). Toxicities were similar in both arms. 
2) Gomez et al. conducted a multi-center Phase II randomized study in 49 patients with up to 3 OM NSCLC with no progression for at least 3 months post 1st line chemotherapy (12, 52). Eighty-four percent were EGFR/ALK negative. Patients were assigned to local therapy (surgery or radical RT) vs. maintenance chemotherapy or observation. Like the previous trial, this study was stopped early due to significant improvements in PFS in the local therapy arm (PFS 14.2 vs. 4.4 months, $P=0.022$ ). OS was also significantly improved (OS 41.2 vs. 17 months, $P=0.017)$. There are two observations from this study. Firstly, the OS benefit was seen despite patients crossing-over from maintenance/observation to local therapy, suggesting earlier local therapy to be superior to local therapy on progression. Secondly, none of the patients suffered from Grade 3 toxicity.

3) Palma et al. conducted the international SABR-COMET Phase II trial including 99 patients with up to $5 \mathrm{OM}$ lesions from a variety of primary histological types (20\% lung primary) (13). Patients were randomized to SBRT to all sites vs. palliative standard of care alone. The primary endpoint, which was OS,

TABLE 2 | Selected ongoing trials of SBRT treatment in oligometastatic NSCLC.

\begin{tabular}{l} 
Title \\
\hline Stereotactic Ablative Radiotherapy for Oligometastatic \\
Non-small Cell Lung Cancer (SARON). A Randomized \\
Phase III Trial. (53) \\
Institution: University College London \\
ClinicalTrials.gov identifier: NCT02417662
\end{tabular}

Maintenance Systemic Therapy vs. Local Consolidative Therapy (LCT) Plus Maintenance Systemic Therapy for Limited Metastatic Non-small Cell Lung Cancer (NSCLC): A Randomized Phase II/II Trial (NRG LU-002) Institution: NRG Oncology

ClinicalTrials.gov identifier: NCT03137771

Randomized Phase III Trial of Local Consolidation Therapy (LCT) After Nivolumab and Ipilimumab for Immunotherapy-Naive Patients With Metastatic Non-small Cell Lung Cancer (LONESTAR) -Strategic Alliance: BMS

Institution: M.D. Anderson Cancer Center ClinicalTrials.gov identifier: NCT03391869

A Randomized Trial of Conventional Care vs. Radioablation (Stereotactic Body Radiotherapy) for Extracranial Oligometastases (CORE) Institution: Royal Marsden NHS Foundation Trust ClinicalTrials.gov identifier: NCT02759783

A Randomized Phase III Trial of Stereotactic Ablative Radiotherapy for the Comprehensive Treatment of 4-10 Oligometastatic Tumors (SABR-COMET 10) Institution: Lawson Health Research Institute ClinicalTrials.gov identifier: NCT03721341

Randomized Phase II Trial of Local Consolidation Therapy (LCT) After Osimertinib for Patients With EGFR Mutant Metastatic Non-small Cell Lung Cancer (NSCLC) (NORTHSTAR)

Institution: M.D. Anderson Cancer Center

ClinicalTrials.gov identifier: NCT03410043

A Multicentre Single Arm Phase II Trial Assessing the Efficacy of Immunotherapy, Chemotherapy and Stereotactic Radiotherapy to Metastases Followed by Definitive Surgery or Radiotherapy to the Primary Tumor, in Patients With Synchronous

Oligo-metastatic NSCLC

Institution: European Thoracic Oncology Platform ClinicalTrials.gov identifier: NCT03965468

\section{Patients Study design}

340

Phase 3 multi-center: chemotherapy alone (standard platinum based doublet chemotherapy or chemotherapy + radical radiotherapy (conventional $\mathrm{RT}$ and $\mathrm{SABR}$ )

Primary histology: all NSCLC

1-3 oligometastatic lesions

Primary outcome measure: OS

$300 \quad$ Phase 2/3 multi-center: maintenance chemotherapy or SBRT + maintenance chemotherapy

Primary histology: all NSCLC

1-3 oligometastatic lesions

Primary outcome measure: PFS

Phase 3 multi-center: systemic treatment only with nivolumab and ipilimumab or induction nivolumab and ipilimumab followed by local consolidative therapy with surgery and/or radiotherapy

Primary histology: all NSCLC

$>1$ oligometastatic lesions

Primary outcome: OS

Phase 2/3 multi-center: standard of care or standard of care + SBRT

Primary histology: breast, prostate, or NSCLC

1-3 oligometastatic lesions

Primary outcome measure: PFS

159 Phase 3 multi-center: stereotactic ablative radiotherapy, plus standard of care treatment: chemotherapy, immunotherapy, hormones, or observation given at the discretion of the treating oncologist

Various histology including NSCLC

4 to 10 oligometastatic lesions

Primary outcome: OS

143 Phase 2 multi-center: osimertinib followed by local consolidative therapy with surgery and/or radiotherapy or maintenance osimertinib alone

Primary histology: NSCLC

Primary outcome: PFS

$47 \quad$ Phase 2 multi-center: durvalumab, carboplatin/paclitaxel chemotherapy, followed by SBRT to all oligometastases. Restaging at 3 months Definitive local treatment with surgical resection of primary tumor or RT 60-66 Gy to the primary tumor if no disease progression.

1-3 oligometastatic lesions

Primary outcome: PFS
$>1$ oligometastatic lesion

Estimated

completion

August 2022

April 2022

December 2022

(

.

October 2024

\section{(}

January 2029

(

$R T$, radiotherapy; SBRT, stereotactic body radiation therapy; SABR, stereotactic ablative radiotherapy; OS, overall survival; PFS, progression free survival. 
was prolonged with addition of SBRT (41 vs. 28 months, $P=$ 0.09 ). Unfortunately, there were significantly more toxicity in the SBRT arm (29 vs. 9\%) with treatment-related death (Grade 5 ) being experienced by three patients (4.5\%).

\section{Phase III Trials}

No Phase III trial has reported the benefit of SBRT in OMNSCLC. In view of the convincing Phase II data, there are multiple ongoing Phase III trials which are eagerly awaited. These trials are summarized in Table 2.

\section{FUTURE DIRECTION AND UNANSWERED QUESTIONS}

Considerable progress has been made in the realm of OMNSCLC. Improvements in survival stem partly from more effective systemic therapy, but also aggressive consolidation therapies (surgery, radiation) in patients with a favorable disease biology. Although the results from randomized Phase II data are exciting, adequately powered Phase III trials with clear inclusion/exclusion criteria (e.g., synchronous, metachronous, oligorecurrence) and appropriate primary endpoints are much awaited to change practice. The upper limit of the number of acceptable OM lesions were set rather arbitrarily. It remains unclear if we should limit this to 3, 5 or 10 (54). As such, two randomized Phase III trials are being planned. SABRCOMET 3 (NCT03862911) for 1-3 lesions, and SABR-COMET 10 (NCT03721341), for 4-10 lesions. Moreover, most of the prospective OM-NSCLC trials have been performed in the

\section{REFERENCES}

1. World Cancer Research Fund/American Institute for Cancer Reaserch. World Cancer Report 2008. Washington, DC: AICR (2008).

2. Walters S, Maringe C, Coleman MP, Peake MD, Butler J, Young N, et al. Lung cancer survival and stage at diagnosis in Australia, Canada, Denmark, Norway, Sweden and the UK: a population-based study, 2004-2007. Thorax. (2013) 68:551-64. doi: 10.1136/thoraxjnl-2012-202297

3. Ramalingam S, Belani C. Systemic chemotherapy for advanced non-small cell lung cancer: recent advances and future directions. Oncologist. (2008) 13 (Suppl. 1):5-13. doi: 10.1634/theoncologist.13-S1-5

4. Goldstraw P, Chansky K, Crowley J, Rami-Porta R, Asamura H, Eberhardt WE, et al. The IASLC lung cancer staging project: proposals for revision of the TNM stage groupings in the forthcoming (eighth) edition of the TNM classification for lung cancer. J Thorac Oncol. (2016) 11:39-51. doi: 10.1016/j.jtho.2015.09.009

5. Hellman S, Weichselbaum RR. Oligometastases. J Clin Oncol. (1995) 13:8-10. doi: 10.1200/JCO.1995.13.1.8

6. Weichselbaum RR, Hellman S. Oligometastases revisited. Nat Rev Clin Oncol. (2011) 8:378-82. doi: 10.1038/nrclinonc.2011.44

7. Fong Y, Fortner J, Sun RL, Brennan MF, Blumgart LH. Clinical score for predicting recurrence after hepatic resection for metastatic colorectal cancer: analysis of 1001 consecutive cases. Ann Surg. (1999) 230:309-18; discussion 318-21. doi: 10.1097/00000658-199909000-00004

8. Leksell L. The stereotaxic method and radiosurgery of the brain. Acta Chir Scand. (1951) 102:316-9.

9. Churilla TM, Chowdhury IH, Handorf E, Collette L, Collette S, Dong Y, et al. Comparison of local control of brain metastases with stereotactic radiosurgery vs surgical resection: a secondary analysis of a randomized clinical trial. JAMA Oncol. (2018) 5:243-7. doi: 10.1001/jamaoncol.2018.4610
Caucasian population where EGFR/ALK driver mutations are known to be much lower than in Asian countries. There remain many unanswered questions about how best to manage these patients including clinical uncertainty if these principles can be extrapolated to populations with higher prevalence of driver mutations. Lastly, most of the studies were conducted prior to the use of immunotherapy. Therefore, the role of SBRT in the context of immunotherapy is uncertain.

\section{CONCLUSION}

Stage IV NSCLC represents a heterogenous group of patients with an overall poor outcome. However, a sub-group of patients with limited metastatic disease may achieve long-term survival with effective systemic therapy and aggressive local therapy. SBRT is a good option to obtain durable local control, and possibly prolong survival for these patients. At the same time, SBRT can be a double-edged sword, with toxicities in a minority of patients. As always, appropriate patient selection remains paramount, and ongoing Phase III trials will provide clarity.

\section{AUTHOR CONTRIBUTIONS}

$\mathrm{CW}, \mathrm{BV}$, and SL contributed conception and design of the study. $\mathrm{CW}$ and $\mathrm{BV}$ organized the database and wrote the first draft of the manuscript. All authors wrote sections of the manuscript, contributed to manuscript revision, read, and approved the submitted version.

10. Potters L, Kavanagh B, Galvin JM, Hevezi JM, Janjan NA, Larson DA, et al. American Society for Therapeutic Radiology and Oncology (ASTRO) and American College of Radiology (ACR) practice guideline for the performance of stereotactic body radiation therapy. Int $J$ Radiat Oncol Biol Phys. (2010) 76:326-32. doi: 10.1016/j.ijrobp.2009. 09.042

11. Iyengar P, Wardak Z, Gerber DE, Tumati V, Ahn C, Hughes RS, et al. Consolidative radiotherapy for limited metastatic non-small-cell lung cancer: a phase 2 randomized clinical trial. JAMA Oncol. (2018) 4:e173501. doi: 10.1001/jamaoncol.2017.3501

12. Gomez DR, Blumenschein GR, Lee JJ, Hernandez M, Ye R, Camidge $\mathrm{DR}$, et al. Local consolidative therapy versus maintenance therapy or observation for patients with oligometastatic non-small-cell lung cancer without progression after first-line systemic therapy: a multicentre, randomised, controlled, phase 2 study. Lancet Oncol. (2016) 17:1672-82. doi: 10.1016/S1470-2045(16)30532-0

13. Palma DA, Olson R, Harrow S, Gaede S, Louie AV, Haasbeek C, et al. Stereotactic ablative radiotherapy versus standard of care palliative treatment in patients with oligometastatic cancers (SABR-COMET): a randomised, phase 2, open-label trial. Lancet. (2019) 393:2051-8. doi: 10.1016/S0140-6736(18)32487-5

14. Dagan R, Lo SS, Redmond KJ, Poon I, Foote MC, Lohr F, et al. A multinational report on stereotactic body radiotherapy for oligometastases: Patient selection and follow-up. Acta Oncol. (2016) 55:633-7. doi: 10.3109/0284186X.2015.1118659

15. Eberhardt WE, Mitchell A, Crowley J, Kondo H, Kim YT, Turrisi A, et al. The IASLC lung cancer staging project: proposals for the revision of the $\mathrm{M}$ descriptors in the forthcoming eighth edition of the TNM classification of lung cancer. J Thorac Oncol. (2015) 10:1515-22. doi: 10.1097/JTO.00000000000 00673 
16. Parikh RB, Cronin AM, Kozono DE, Oxnard GR, Mak RH, Jackman DM, et al. Definitive primary therapy in patients presenting with oligometastatic non-small cell lung cancer. Int J Radiat Oncol Biol Phys. (2014) 89:880-7. doi: 10.1016/j.ijrobp.2014.04.007

17. Lo SS, Moffatt-Bruce SD, Dawson LA, Schwarz RE, Teh BS, Mayr NA, et al. The role of local therapy in the management of lung and liver oligometastases. Nat Rev Clin Oncol. (2011) 8:405-16. doi: 10.1038/nrclinonc.2011.75

18. Niibe Y, Hayakawa K. Oligometastases and oligo-recurrence: the new era of cancer therapy. Jpn J Clin Oncol. (2010) 40:107-11. doi: 10.1093/jjco/hyp167

19. National Comprehensive Cancer Network. Non-small Cell Lung Cancer. Version 7.2019. (2019). Available online at: https://www.nccn.org/ professionals/physician_gls/pdf/nscl.pdf (accessed November 2, 2019).

20. Lewis SL, Porceddu S, Nakamura N, Palma DA, Lo SS, Hoskin P, et al. Definitive stereotactic body radiotherapy (SBRT) for extracranial oligometastases: an international survey of $>1000$ radiation oncologists. Am J Clin Oncol. (2017) 40:418-22. doi: 10.1097/COC.0000000000000169

21. Liu ES, Stenmark MH, Lee OE, Schipper MJ, Caoili EM, Ben-Josef E, et al. SBRT as an alternative to RFA for the treatment of primary and metastatic liver tumors. J Clin Oncol. (2012) 30:158. doi: 10.1200/jco.2012.30.4_suppl.158

22. Timmerman RD, Bizekis CS, Pass HI, Fong Y, Dupuy DE, Dawson LA, et al. Local surgical, ablative, and radiation treatment of metastases. CA Cancer J Clin. (2009) 59:145-70. doi: 10.3322/caac.20013

23. Widder J, Klinkenberg TJ, Ubbels JF, Wiegman EM, Groen HJ, Langendijk JA. Pulmonary oligometastases: metastasectomy or stereotactic ablative radiotherapy? Radiother Oncol. (2013) 107:409-13. doi: 10.1016/j.radonc.2013.05.024

24. Tanadini-Lang S, Rieber J, Filippi AR, Fode MM, Streblow J, Adebahr S, et al. Nomogram based overall survival prediction in stereotactic body radiotherapy for oligo-metastatic lung disease. Radiother Oncol. (2017) 123:182-8. doi: 10.1016/j.radonc.2017.01.003

25. Ashworth AB, Senan S, Palma DA, Riquet M, Ahn YC, Ricardi U, et al. An individual patient data metaanalysis of outcomes and prognostic factors after treatment of oligometastatic non-small-cell lung cancer. Clin Lung Cancer. (2014) 15:346-55. doi: 10.1016/j.cllc.2014.04.003

26. Albain KS, Crowley JJ, LeBlanc M, Livingston RB. Survival determinants in extensive-stage non-small-cell lung cancer: the Southwest Oncology Group experience. J Clin Oncol. (1991) 9:1618-26. doi: 10.1200/JCO.1991.9.9.1618

27. Andrews DW, Scott CB, Sperduto PW, Flanders AE, Gaspar LE, Schell $\mathrm{MC}$, et al. Whole brain radiation therapy with or without stereotactic radiosurgery boost for patients with one to three brain metastases: phase III results of the RTOG 9508 randomised trial. Lancet. (2004) 363:1665-72. doi: 10.1016/S0140-6736(04)16250-8

28. Salama JK, Hasselle MD, Chmura SJ, Malik R, Mehta N, Yenice KM, et al. Stereotactic body radiotherapy for multisite extracranial oligometastases: final report of a dose escalation trial in patients with 1 to 5 sites of metastatic disease. Cancer. (2012) 118:2962-70. doi: 10.1002/cncr.26611

29. Bergsma DP, Salama JK, Singh DP, Chmura SJ, Milano MT. Radiotherapy for oligometastatic lung cancer. Front Oncol. (2017) 7:210. doi: $10.3389 /$ fonc.2017.00210

30. De Rose F, Cozzi L, Navarria P, Ascolese AM, Clerici E, Infante M, et al. Clinical outcome of stereotactic ablative body radiotherapy for lung metastatic lesions in non-small cell lung cancer oligometastatic patients. Clin Oncol. (2016) 28:13-20. doi: 10.1016/j.clon.2015.08.011

31. Navarria P, Ascolese AM, Tomatis S, Cozzi L, De Rose F, Mancosu P, et al. Stereotactic body radiotherapy (sbrt) in lung oligometastatic patients: role of local treatments. Radiat Oncol. (2014) 9:91. doi: 10.1186/1748-717X-9-91

32. Villaruz LC, Kubicek GJ, Socinski MA. Management of non-small cell lung cancer with oligometastasis. Curr Oncol Rep. (2012) 14:333-41. doi: 10.1007/s11912-012-0240-1

33. Voltolini L, Rapicetta C, Luzzi L, Ghiribelli C, Paladini P, Granato F, et al. Surgical treatment of synchronous multiple lung cancer located in a different lobe or lung: high survival in node-negative subgroup. Eur J Cardiothorac Surg. (2010) 37:1198-204. doi: 10.1016/j.ejcts.2009.11.025

34. Rieber J, Abbassi-Senger N, Adebahr S, Andratschke N, Blanck O, Duma $\mathrm{M}$, et al. Influence of institutional experience and technological advances on outcome of stereotactic body radiation therapy for oligometastatic lung disease. Int J Radiat Oncol Biol Phys. (2017) 98:511-20. doi: 10.1016/j.ijrobp.2016.09.026
35. Rieber J, Streblow J, Uhlmann L, Flentje M, Duma M, Ernst I, et al. Stereotactic body radiotherapy (SBRT) for medically inoperable lung metastases-A pooled analysis of the German working group "stereotactic radiotherapy". Lung Cancer. (2016) 97:51-8. doi: 10.1016/j.lungcan.2016.04.012

36. Ahmed KA, Caudell JJ, El-Haddad G, Berglund AE, Welsh EA, Yue $B$, et al. Radiosensitivity differences between liver metastases based on primary histology suggest implications for clinical outcomes after stereotactic body radiation therapy. Int J Radiat Oncol Biol Phys. (2016) 95:1399-404. doi: 10.1016/j.ijrobp.2016.03.050

37. Riihimäki M, Hemminki A, Fallah M, Thomsen H, Sundquist K, Sundquist J, et al. Metastatic sites and survival in lung cancer. Lung Cancer. (2014) 86:78-84. doi: 10.1016/j.lungcan.2014.07.020

38. Tamura T, Kurishima K, Nakazawa K, Kagohashi K, Ishikawa H, Satoh H, et al. Specific organ metastases and survival in metastatic non-small-cell lung cancer. Mol Clin Oncol. (2015) 3:217-21. doi: 10.3892/mco.2014.410

39. Milano MT, Katz AW, Muhs AG, Philip A, Buchholz DJ, Schell MC, et al. A prospective pilot study of curative-intent stereotactic body radiation therapy in patients with 5 or fewer oligometastatic lesions. Cancer. (2008) 112:650-8. doi: $10.1002 /$ cncr.23209

40. Rusthoven KE, Kavanagh BD, Cardenes H, Stieber VW, Burri SH, Feigenberg SJ, et al. Multi-institutional phase I/II trial of stereotactic body radiation therapy for liver metastases. J Clin Oncol. (2009) 27:1572-8. doi: 10.1200/JCO.2008.19.6329

41. Andratschke N, Alheid H, Allgäuer M, Becker G, Blanck O, Boda-Heggemann J, et al. The SBRT database initiative of the German Society for Radiation Oncology (DEGRO): patterns of care and outcome analysis of stereotactic body radiotherapy (SBRT) for liver oligometastases in 474 patients with 623 metastases. BMC Cancer. (2018) 18:283. doi: 10.1186/s12885-0184191-2

42. Celik E, Semrau R, Baues C, Trommer-Nestler M, Baus W, Marnitz S. Robot-assisted extracranial stereotactic radiotherapy of adrenal metastases in oligometastatic non-small cell lung cancer. Anticancer Res. (2017) 37:5285-91. doi: 10.21873/anticanres.11954

43. Holy R, Piroth M, Pinkawa M, Eble MJ. Stereotactic body radiation therapy (SBRT) for treatment of adrenal gland metastases from non-small cell lung cancer. Strahlenther Onkol. (2011) 187:245-51. doi: $10.1007 / \mathrm{s} 00066-011-2192-\mathrm{z}$

44. Rudra S, Malik R, Ranck MC, Farrey K, Golden DW, Hasselle MD, et al. Stereotactic body radiation therapy for curative treatment of adrenal metastases. Technol Cancer Res Treat. (2013) 12:217-24. doi: $10.7785 /$ tcrt.2012.500320

45. Oshiro Y, Takeda Y, Hirano S, Ito H, Aruga T. Role of radiotherapy for local control of asymptomatic adrenal metastasis from lung cancer. Am J Clin Oncol. (2011) 34:249-53. doi: 10.1097/COC.0b013e3181dbb727

46. Rusthoven KE, Hammerman SF, Kavanagh BD, Birtwhistle MJ, Stares $\mathrm{M}$, Camidge DR. Is there a role for consolidative stereotactic body radiation therapy following first-line systemic therapy for metastatic lung cancer? A patterns-of-failure analysis. Acta Oncol. (2009) 48:578-83. doi: $10.1080 / 02841860802662722$

47. Inoue $\mathrm{T}$, Katoh $\mathrm{N}$, Aoyama $\mathrm{H}$, Onimaru $\mathrm{R}$, Taguchi $\mathrm{H}$, Onodera $\mathrm{S}$, et al. Clinical outcomes of stereotactic brain and/or body radiotherapy for patients with oligometastatic lesions. Jpn J Clin Oncol. (2010) 40:788-94. doi: 10.1093/jico/hyq044

48. Hasselle MD, Haraf DJ, Rusthoven KE, Golden DW, Salgia R, Villaflor VM, et al. Hypofractionated image-guided radiation therapy for patients with limited volume metastatic non-small cell lung cancer. J Thorac Oncol. (2012) 7:376-81. doi: 10.1097/JTO.0b013e31824166a5

49. De Ruysscher D, Wanders R, van Baardwijk A, Dingemans AM, Reymen B, Houben R, et al. Radical treatment of non-small-cell lung cancer patients with synchronous oligometastases: long-term results of a prospective phase II trial (Nct01282450). J Thorac Oncol. (2012) 7:1547-55. doi: 10.1097/JTO.0b013e318262caf6

50. Collen C, Christian N, Schallier D, Meysman M, Duchateau M, Storme G, et al. Phase II study of stereotactic body radiotherapy to primary tumor and metastatic locations in oligometastatic nonsmall-cell lung cancer patients. Ann Oncol. (2014) 25:1954-9. doi: 10.1093/annonc/mdu370

51. Bauml JM, Mick R, Ciunci C, Aggarwal C, Davis C, Evans T, et al. Pembrolizumab after completion of locally ablative therapy for 
oligometastatic non-small cell lung cancer: a phase 2 trial. JAMA Oncol. (2019) 5:1283-90 doi: 10.1001/jamaoncol.2019.1449

52. Gomez DR, Tang C, Zhang J, Blumenschein GR Jr, Hernandez M, Lee JJ, et al. Local consolidative therapy vs. maintenance therapy or observation for patients with oligometastatic non-small-cell lung cancer: long-term results of a multi-institutional, phase ii, randomized study. J Clin Oncol. (2019) 37:1558-65. doi: 10.1200/JCO.19. 00201

53. Conibear J, Chia B, Ngai Y, Bates AT, Counsell N, Patel R, et al. Study protocol for the SARON trial: a multicentre, randomised controlled phase III trial comparing the addition of stereotactic ablative radiotherapy and radical radiotherapy with standard chemotherapy alone for oligometastatic non-small cell lung cancer. BMJ Open. (2018) 8:e020690. doi: 10.1136/bmjopen-2017-020690

54. Yamamoto M, Serizawa T, Shuto T, Akabane A, Higuchi Y, Kawagishi J, et al. Stereotactic radiosurgery for patients with multiple brain metastases (JLGK0901): a multi-institutional prospective observational study. Lancet Oncol. (2014) 15:387-95. doi: 10.1016/S1470-2045(14) 70061-0
Conflict of Interest: SS reports grants from Varian Industries outside the submitted work. AL reports personal fees from Varian Medical Systems Inc. outside the submitted work. The Department of Radiation Oncology at VU University Medical Center has a research collaboration with Varian Medical Systems. BS has received honoraria and/or travel support from Varian Medical Systems and ViewRay. SL reports research support from Elekta AB in Elekta Gamma Knife ICON Expert Group outside of submitted work.

The remaining authors declare that the research was conducted in the absence of any commercial or financial relationships that could be construed as a potential conflict of interest.

Copyright (C) 2019 Wujanto, Vellayappan, Siva, Louie, Guckenberger, Slotman, Onishi, Nagata, Liu and Lo. This is an open-access article distributed under the terms of the Creative Commons Attribution License (CC BY). The use, distribution or reproduction in other forums is permitted, provided the original author(s) and the copyright owner(s) are credited and that the original publication in this journal is cited, in accordance with accepted academic practice. No use, distribution or reproduction is permitted which does not comply with these terms. 